\title{
A Conceptual Model of Personal Health Record for Autistic Patients
}

\section{Fateme Moghbeli1 ${ }^{(\mathbb{D})}$, Tina Adel ${ }^{2}$, Mostafa Langarizadeh ${ }^{3 *}$, Mitra Hakim Shoushtari ${ }^{4}(\mathbb{D}$}

${ }^{1} \mathrm{PhD}$ of Medical Informatics, Iran University of Medical Sciences, Tehran, Iran.

${ }^{2}$ School of Health Management and Information Sciences, Iran University of Medical Sciences, Tehran, Iran.

${ }^{3}$ Assistant Professor, Department of Health information Management, School of Health Management and Information Sciences, Iran University of Medical Sciences, Tehran, Iran

${ }^{4}$ Associate Professor, Department of Psychiatry, Mental Health Research Center, Tehran Institute of Psychiatry, Faculty of Behavioral Sciences and Mental Health, Iran University of Medical Sciences, Tehran, Iran.

\begin{tabular}{l}
\hline Article Info \\
\hline Article type: \\
Research \\
\hline Article History: \\
Received: 2019-08-17 \\
Revised: - \\
Accepted: 2019-08-31 \\
\\
\hline *Corresponding author: \\
Mostafa Langarizadeh \\
Assistant Professor, Department of \\
Health information Management, \\
School of Health Management and \\
Information Sciences, Iran University \\
of Medical Sciences, Tehran, Iran. \\
Email: Langarizadeh.m@iums.ac.ir
\end{tabular}

A B S T R A C T

\section{Introduction:}

The personal health record of patient with autism has not been adequately addressed. While, these records play an important role to provide a good perspective on how to diagnose autism, negotiating, coordinating and designing services and interventions by families and physicians during delivery of multiple services. The present study is aimed to present a conceptual model of electronic personal health record for patients with autism.

\section{Material and Methods:}

This study was conducted on six psychiatric practitioners and six pediatricians from Rasoul Akram Hospital and Ali Asghar Hospital with purposeful sampling. A questionnaire has been used for data gathering and identifying information needs. The content validity was measured using expert panel method and test-retest method $(\mathrm{r}=0.79)$ was used to perform the reliability. Data analysis was done using descriptive statistics with SPSS version 23 software. In the design phase, graphs were plotted using Visio software.

\section{Results:}

According to the findings, the most important data elements of the conceptual model of the personal health record for patients with autism from the viewpoint of physicians are divided into demographic data segments, clinical data and individual function level (based on valid clinical scales) such as general clinical measure (by the physician, types of interventions, prenatal or near-births, registration of symptoms of parental impairment, examination of the course and prognosis based on the Gylliam Autism Rating Scale every six months by a psychologist and other psychiatric diagnoses.

\section{Conclusion:}

Since autism patients' long life clinical information plays an important role in diagnosis and management of patients' clinical problems, the conceptual model of personal health record for patients with autism could have a significant effect in managing and integrating patient clinical information, increasing the quality of care, and reducing the cost.

Keywords:

Personal Health Record, Autism, Conceptual Model, Unified Modeling Language.

How to cite this paper

Moghbeli F, Adel T, Langarizadeh M, Hakim Shoushtari M. A Conceptual Model of Personal Health Record for Autistic Patients. 2019; 8(1): e18. DOI: 10.30699/fhi.v8i1.197

\section{INTRODUCTION}

Autism is a group of developmental disabilities that is associated with impaired social interaction and limited communication, repetitive and stereotyped patterns of behavior, inability to develop language and fast behaviors. Symptoms of this disease usually appear at the age of less than three years [1- $\underline{3}]$. Classifications of Autism Spectrum Disorders (ASD) 
include Autism Disorder, Asperger Disorder, Rett Syndrome, Childhood Disintegrative Disorder, and Pervasive Developmental Disorder-Not. Otherwise Specified) [4]. The prevalence of autism is increasing day by day and has become a public health concern and is today recognized as the most common developmental disorder $[\underline{4} \underline{5}]$. According to statistics provided by the World Health Organization, one in every 160 children worldwide has a child with autism. According to the American Autism Society, about 1.5 million Americans live with the effects of autism. According to reports from families, the prevalence of autism has risen to more than 11 per 1,000 people, which has grown significantly over the past ten years $[\underline{4}, \underline{6}, \underline{7}]$.

The prevalence of autism in Iran among children under the age of 5 is 26.26 per 10,000 people, which is similar to previous reports from European countries and Hong Kong. Recent studies on the prevalence of autism in Iran have been conducted recently, including a preliminary study by Ghanizadeh in primary schools, which reported a prevalence of 19 per 1000 people for autism. However, the prevalence rate of autism in Iran is lower than in Sweden, the United States, and the United Kingdom. One possible reason for this low incidence rate may be the lack of coherent and integrated health information in this area $[\underline{8}, \underline{9}]$.

Early detection of the disease reduces the long-term concerns of many families and accelerates opportunities for medical interventions and reduces family and community costs $[\underline{10}, \underline{11}]$. On the other hand, since autism and its effects will always be with the affected person and his or her family, it is necessary to have a coherent information system that can integrate the health information of these patients into one. Due to the wide range of autism patients and the high cost of treatment for their families, providing a conceptual model of personal health records for these patients can reduce the cost of treatment and increase the cost of treatment in addition to the positive impact on quality of care and care for these patients. Use of personal health records in other areas $[\underline{12}, \underline{13}]$.

Emphasis on health informatics has led to the emergence and strengthening of systems such as the Electronic Personal Health Record (ePHR) that enable patient participation, information sharing, communication and facilitation. It provides care and reduces medical costs [14]. Personal Health Electronic Records In addition to storing personal health information, other information can also be included, including drug interference checking, patient and email exchanges, health care appointment management, accessibility The patient has access to a wide range of sources of health information and the best medical practices, access to medical records in emergency situations and the like
[15]. This file may include a variety of data such as person's identity information, health care providers, health insurance, major illnesses, drugs used, vaccinations, allergies, drug allergies, individual tests and results. The American Standards Institute's Standards Requirements and Planning Committee defines three distinct levels for describing data in a database or database architecture [16].

- Concept Conceptual data model

- External data model

- Internal data model

The conceptual model helps to understand the entities and how they interact with each other. It can also be described as a model made up of concepts and relationships between them. Since integrated modeling language describes real systems, it is important to develop a conceptual model and to gradually improve it [17].

Based on the search, no study was found to develop an electronic personal health record of patients with autism or to provide a conceptual model of it in Iran. Therefore, such an innovative study can be an important step in regulating the status of these patients in health care systems. The purpose of the present study was to present and validate a conceptual model of personal electronic health records for patients with autism based on the needs of physicians and psychiatrists involved in the treatment of these patients to integrate diverse medical information, increase quality of care, and reduce medical and diagnostic costs.

\section{MATERIAL AND METHODS}

This applied research was conducted in two stages. Firstly, by studying library resources, the data elements used in the electronic health records of patients with autism were identified and a questionnaire was prepared based on it. The questionnaire was distributed among pediatric and pediatric psychiatrists in order to incorporate the conceptual model of their viewpoints that are closely related to autism patients as well as the shortcomings and limitations of the treatment process. The questionnaire generally had two sets of suggestions, demographic data and clinical data as input data for the EHR.

Validity of the questionnaire was determined based on the opinion of pediatrician and psychiatrist. Reliability of the instrument was assessed by testretest method. The questionnaire was distributed among all pediatric and pediatric psychiatrists of Rasoul Akram Educational and Research Complex and Ali Asghar Educational and Medical Center (including 12 pediatricians and 10 psychiatrists). The data were collected by visiting the researcher in 
person. Due to the unwillingness of a number of specialist physicians to cooperate, an explanation was given about their research goals. Data obtained from the Physician Needs Assessment Questionnaire using SPSS 23 software, were considered as necessary and necessary items that at least $60 \%$ of the respondents considered it necessary in the model.

Secondly, the design and validation of a conceptual model of personal health electronic records for patients with autism was performed. Users of the individual health record (physician, patient) must have clear access to the system and be able to perform their required operations as prescribed. At this stage, based on the results of the previous step, using the Unified Modeling Language (UML), the class diagrams and applications were designed and validated according to the expert opinion. These included 15 pediatric and psychiatric physicians and 15 health information management and medical informatics specialists located at Rasoul Akram Hospital and other hospitals affiliated to Iran University of Medical Sciences, Tehran and Shahid Beheshti. It was forensic medicine and medical management and information at these universities. Data were analyzed using SPSS 23 software. If more than $75 \%$ of respondents agree on each case, the data is confirmed. If $50 \%$ to $75 \%$ of respondents were positive, they would be considered again in the next round, and if less than $50 \%$ of respondents were positive, the proposed model would be removed.

\section{RESULTS}

This study was designed to present a conceptual model of individual health records of patients with autism.

Table 1 shows the characteristics of the participants in the first phase of the study. According to this table, $66.7 \%$ of psychiatrists and $50 \%$ of pediatricians were men and the rest were women. In general, the proportion of men in the research community was higher than women. Also, the highest age group (100\%) belonged to the age group below 40 and the majority of participants (91.7\%) had work experience less than five years.

After extracting the information from the questionnaires and analyzing them, only those cases with at least $60 \%$ of participants agreeing in the electronic health record were selected. For demographic data, 8 items were chosen by name, father's name, national code, age, sex, marital status, address and telephone. Also, according to the results, the participants did not find the CT scan results necessary in the patient's health record, and confirmed the rest.

Based on the opinions of the participants, the usability of the electronic health record of autistic patients was also determined and used in the form of class diagrams. For example, Figures 1 to 3 illustrate the diagram used for data entry and the different physician and patient accesses for data entry into the Patient Health Record, Patient Information Subsystem, and Physician Information Subsystem, respectively. Figure 4 shows the class diagram of the Electronic Health Record.

Table 1: Characteristics of the participants

\begin{tabular}{|c|c|c|c|c|c|c|c|}
\hline \multirow{2}{*}{\multicolumn{2}{|c|}{ Demographic sample }} & \multicolumn{2}{|c|}{ 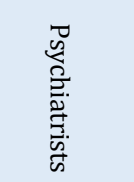 } & \multicolumn{2}{|c|}{ 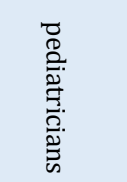 } & \multicolumn{2}{|c|}{$\begin{array}{l}\overrightarrow{0} \\
\text { Dे } \\
\text { D }\end{array}$} \\
\hline & & $\mathrm{N}$ & $\%$ & $\mathrm{~N}$ & $\%$ & $\mathrm{~N}$ & $\%$ \\
\hline \multirow[t]{3}{*}{ Age } & $<40$ & 6 & 100 & 6 & 100 & 12 & 100 \\
\hline & $40-50$ & 0 & 0 & 0 & 0 & 0 & 0 \\
\hline & $50<$ & 0 & 0 & 0 & 0 & 0 & 0 \\
\hline \multirow{3}{*}{$\begin{array}{l}\text { Work } \\
\text { experience }\end{array}$} & $<5$ & 5 & 83.3 & 6 & 100 & 11 & 91.7 \\
\hline & $5-10$ & 1 & 16.7 & 0 & 0 & 1 & 8.3 \\
\hline & $10<$ & 0 & 0 & 0 & 0 & 0 & 0 \\
\hline \multirow[t]{2}{*}{ Gender } & Female & 2 & 33.3 & 3 & 50 & 5 & 41.7 \\
\hline & Male & 4 & 66.7 & 3 & 50 & 7 & 58.3 \\
\hline
\end{tabular}

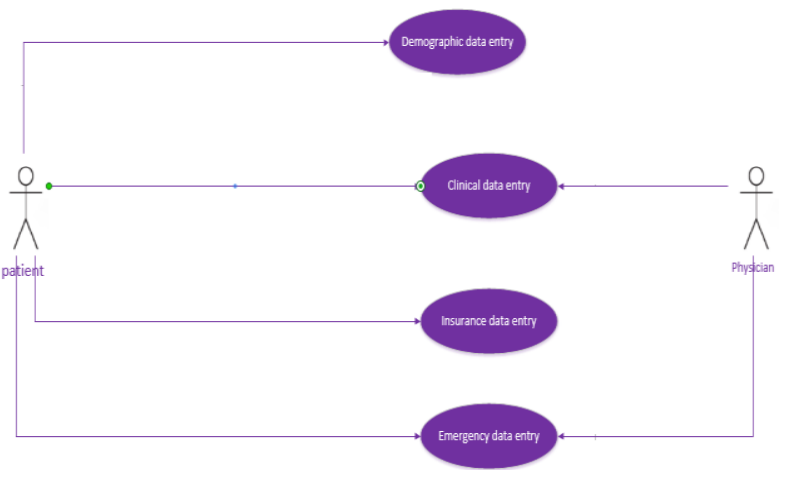

Fig 1: Use case diagram for entering data into a patient's health record

In the next step, a questionnaire based on the obtained charts was prepared and distributed to health information management professionals, medical informatics and psychiatrists and pediatricians. Based on the results of these questionnaires, more than $70 \%$ of participants reported the portions agreed, so the chart remained unchanged in the final margin. The characteristics of the participants in the second part of the study are reported in Table 2 . 


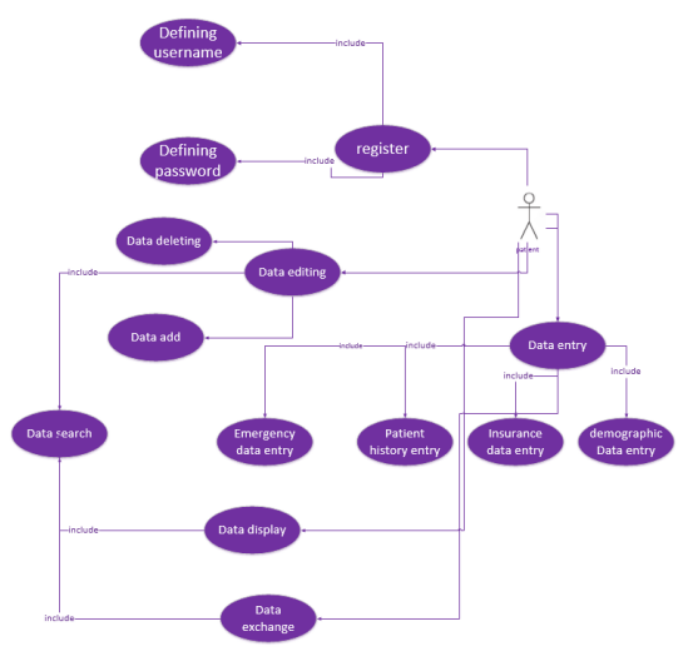

Fig 2: Use case diagram of patient information subsystem

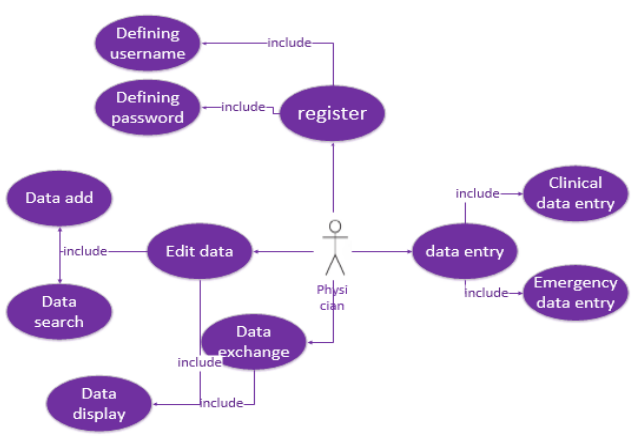

Fig 3: Use case diagram of the physician information system

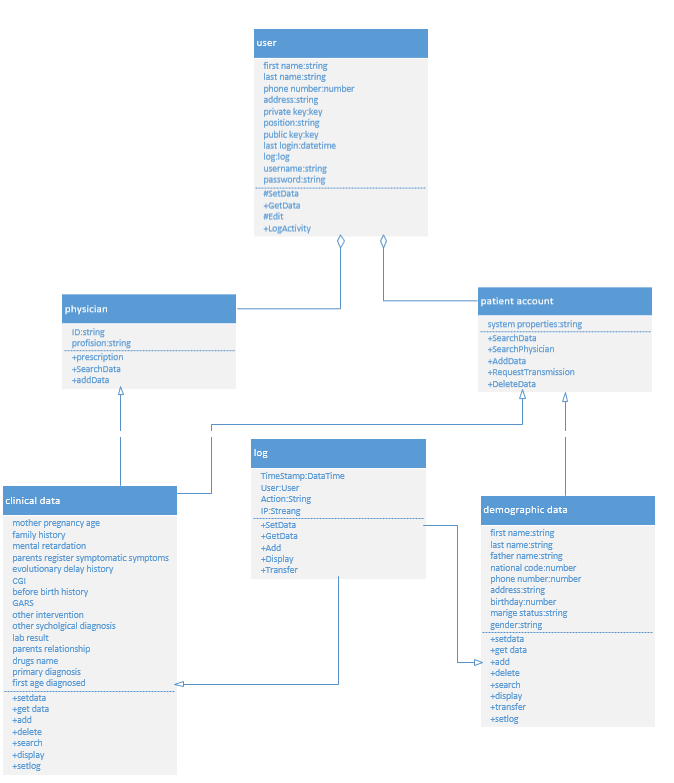

Fig 4: Health chart of individual health records of patients with autism

Among the participants, $28.6 \%$ were medical informatics specialists, $23.8 \%$ health information management specialists, $28.6 \%$ psychiatrists and
$19 \%$ pediatricians. In general, the proportion of women in the community was higher than men, the highest age group was under $40(57.2 \%)$ and the majority of participants had work experience between five and 10 years (66.6\%).

\section{DISCUSSION}

In this study, after determining the elements of the individual health records of patients with autism, the minimum set of data for this system was determined from the physicians' perspective, which included demographic and clinical data.

In his research entitled "Evaluating the Information Needs of Electronic Diagnosis of Diabetes Patients' Health from the Perspective of Endocrinologists" in the demographic information section of age (6.9\%), in the anthropometric information section of body mass index (9.5\%), General information about smoking history $(5.9 \%)$, section on recent medical treatment information $(7.9 \%)$, Insulin treatment patient information (9\%), laboratory tests (6.9\%) and section Patient referral to the clinic considers the diabetic foot clinic one of the most important elements of the electronic health record of diabetic patients from the point of view of endocrinologists [18].

In this study, after determining the data elements based on the study of relevant literature, the minimum set of individual health records was determined based on a survey of pediatric and psychiatric specialists.

In Scott's 2007 study "Assessing the Information Needs of Myocardial Infarction Patients", information on risk factors was ranked as the most important category, after which information on cardiac anatomy, drug physiology, and physical activity was considered important and item information Miscellaneous, diet, psychological factors, and the cardiac care unit, although still low, are still important [19].

In the present study, after creating an account with users in the system, the patient will be able to enter their clinical information upon request. Finally, after the physician has created an account, the physician will also be able to view the patient's history and the patient's clinical data based on the defined access level.

Finally, after reviewing the data needs of individual health records of patients with autism, the data needs of users are plotted as diagrams. The diagram used to organize and model system behaviors is of great importance. Using the diagrams used, the class diagrams and activities were designed. In this study, the patient is identified as the main actor and the physician as the other model actors. In his 2013 Hospital Management Project, Shaker included class 
charts including patient classes, enrollment, scheduling, editing, reports, examinations, and

individual hospital departments [19].

Table 2: Distribution of demographic status of research participants

\begin{tabular}{|c|c|c|c|c|c|c|c|c|c|c|c|}
\hline \multirow{2}{*}{\multicolumn{2}{|c|}{ Demographic sample }} & \multicolumn{2}{|c|}{ 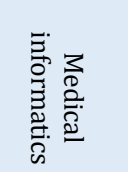 } & \multicolumn{2}{|c|}{ 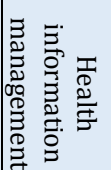 } & \multicolumn{2}{|c|}{ 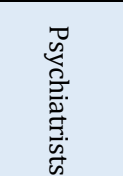 } & \multicolumn{2}{|c|}{ 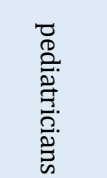 } & \multicolumn{2}{|c|}{$\stackrel{0}{0}$} \\
\hline & & $\mathrm{N}$ & $\%$ & $\mathrm{~N}$ & $\%$ & $\mathrm{~N}$ & $\%$ & $\mathrm{~N}$ & $\%$ & $\mathrm{~N}$ & $\%$ \\
\hline \multirow[t]{3}{*}{ Age } & $<40$ & 4 & 66.7 & 3 & 60 & 3 & 50 & 2 & 50 & 12 & 57.2 \\
\hline & $40-50$ & 2 & 33.3 & 2 & 40 & 3 & 50 & 2 & 50 & 9 & 42.8 \\
\hline & $50<$ & 0 & 0 & 0 & 0 & 0 & 0 & 0 & 0 & 0 & 0 \\
\hline \multirow{3}{*}{$\begin{array}{r}\text { Work } \\
\text { experience }\end{array}$} & $<5$ & 1 & 16.7 & 0 & 0 & 0 & 0 & 0 & 0 & 1 & 4.8 \\
\hline & $5-10$ & 4 & 66.7 & 4 & 80 & 4 & 66.7 & 2 & 50 & 14 & 66.6 \\
\hline & $<10$ & 1 & 16.7 & 1 & 20 & 2 & 33.3 & 2 & 50 & 6 & 28.6 \\
\hline \multirow[t]{2}{*}{ Gender } & Female & 3 & 50 & 2 & 50 & 4 & 66.7 & 2 & 50 & 12 & 57.2 \\
\hline & Male & 3 & 50 & 2 & 50 & 2 & 33.3 & 2 & 50 & 9 & 42.8 \\
\hline
\end{tabular}

In this study, the class diagram includes patient, physician, user, entry and exit class, clinical data and demographic data.

\section{CONCLUSION}

In this research, provider information is also presented in the class related to the provider. To develop an individual health record system, it is recommended that the data needs are appropriately identified, analyzed and plotted using charts. Then, draw on the charts used, the other charts to draw an integrated picture of the individual health record system. This will certainly have a positive and significant role to play in enhancing the quality of the service delivery system.

\section{AUTHOR'S CONTRIBUTION}

All the authors approved the final version of the manuscript.

\section{CONFLICTS OF INTEREST}

The authors declare no conflicts of interest regarding the publication of this study.

\section{FINANCIAL DISCLOSURE}

No financial interests related to the material of this manuscript have been declared.

\section{REFERENCES}

1. Baio J. Prevalence of autism spectrum disorders: Autism and developmental disabilities monitoring network, 14 sites, united states, 2008. Morbidity and mortality weekly report. Surveillance Summaries. 2012; 61(3): 1-19.

2. Shen Y, Dies KA, Holm IA, Bridgemohan C, Sobeih $\mathrm{MM}$, Caronna EB, et al. Clinical genetic testing for patients with autism spectrum disorders. Pediatrics. 2010; 125(4): e727-35. PMID: 20231187 DOI: 10.1542/peds.2009-1684 [PubMed]

3. National Collaborating Centre for Mental Health (UK). Autism: Recognition, referral, diagnosis and management of adults on the autism spectrum. British Psychological Society. 2012.

4. Kim SK. Recent update of autism spectrum disorders. Korean J Pediatr. 2015 Jan; 58(1): 8-14. PMID: 25729393 DOI: 10.3345/kjp.2015.58.1.8 [ubMed]

5. Bauer NS, Carroll AE, Saha CK, Downs SM. Computer decision support changes physician practice but not knowledge regarding autism spectrum disorders. Appl Clin Inform. 2015; 6(3): 454-465. PMID: 26448791 DOI: $10.4338 / \mathrm{ACI}-2014-09-\mathrm{RA}-0084$ [PubMed]

6. McPartland J, Volkmar FR. Autism and related disorders. Handb Clin Neurol. Handbook of clinical neurology. 2012;106: 1-18. PMID: 22608634 doi: 10.1016/B978-0-444-52002-9.00023-1 [PubMed]

7. World Health Organization. Autism spectrum disorders [Internet]. 2016 [cited 1 Mar 2019]. Available from: http://www.who.int/mediacentre /factsheets/autism-spectrum-disorders/en./

8. Samadi SA, McConkey R. Autism in developing countries: Lessons from Iran. Autism Research and Treatment. 2011; 2011: 1-11.

9. Mohammadi MR, Salmanian M, Akhondzadeh S. 
Autism spectrum disorders in Iran. Iranian Journal of Child Neurology. 2011; 5(4): 1-9.

10. Anagnostou E, Zwaigenbaum L, Szatmari $P$, Fombonne E, Fernandez BA, Woodbury-Smith M, et al. Autism spectrum disorder: Advances in evidencebased practice. CMAJ. 2014; 186(7): 509-19. PMID: 24418986 DOI: $10.1503 / \mathrm{cmaj} .121756$ [PubMed]

11. Reed P, Picton L, Grainger N, Osborne LA. Impact of diagnostic practices on the self-reported health of mothers of recently diagnosed children with ASD. Int J Environ Res Public Health. 2016 Sep 7;13(9). pii: E888. PMID: 27618075 DOI: 10.3390/ijerph13090888 [PubMed]

12. Cohn SP. Letter report to the secretary of health and human services on personal health record systems [Internet]. 2005 [cited: 1 May 2008]. Available from: www.ncvhs.hhs.gov/0509091t.htm.

13. Cimino JJ, Patel VL, Kushniruk AW. What do patients do with access to their medical records? Stud Health Technol Inform. 2001; 84(2): 1440-4. PMID: 11604964 [PubMed]

14. Samadpour H, Sadoughi F. Data set of electronic personal health records for iranian students of medical sciences. Health Information Management. 2015; 12(4): 416-25.

15. Angier H, Gold R, Crawford C, O'Malley JP, Tillotson CJ, Marino M, et al. Linkage methods for connecting children with parents in electronic health record and state public health insurance data. Matern Child Health J. 2014; 18(9): 2025-33. PMID: 24562505 DOI: $10.1007 / \mathrm{s} 10995-014-1453-8$ [PubMed]

16. Angell AM, Solomon 0 . The social life of health records: Understanding families' experiences of autism. Social Science \& Medicine. 2014; 117: 50-7.

17. Sadoughi F, Samadbeik M, Ehteshmi A, Aminpor F, Rezaei P. Health information technology. Jafari Publication, Tehran; 2011.

18. Babolhavaeji F, Emami Z, Shahrokhi R. Evaluating the information requirements of the electronic health record for diabetic patients from the point of view of endocrinologists. Journal of Healthcare Management. 2014; 5(2): 13-24.

19. Scott JT, Thompson DR. Assessing the information needs of post-myocardial infarction patients: A systematic review. Patient Educ Couns. 2003; 50(2): 167-77. PMID: 12781932 [PubMed] 